Agrotrópica 33(1): 5 - 16. 2021.

Centro de Pesquisas do Cacau, Ilhéus, Bahia, Brasil

\title{
AVALIAÇÃO DE CLONES DE CACAUEIRO QUANTO A PRODUTIVIDADE E INCIDÊNCIA DE VASSOURA DE BRUXA E PODRIDÃO PARDA
}

\author{
Mariosvaldo Macêdo ${ }^{1}$, Eimar Sampaio Rosa², Edna Dora Martins Newman Luz ${ }^{1}$, José Luis \\ Pires $^{1 *}$ \\ ${ }^{1}$ CEPLAC/CEPEC - km 22, Rod. Ilhéus/Itabuna, 45600-970, Ilhéus, Bahia, Brasil. ${ }^{2}$ Avenida Soares Lopes, 1628. Apart. 502 \\ centro, 45652-065, Ilhéus, Bahia. \\ *Autor para correspondência: joseluiszoegapires@gmail.com
}

\begin{abstract}
Foram avaliados, em um sistema de blocos incompletos, 179 clones de cacaueiro, em 79 locais, por um período de 11 anos. A maioria destes clones deriva de um processo de seleção para resistência e produtividade conduzido por toda a região cacaueira da Bahia, e foram aqui escolhidos os aparentemente mais promissores dentre os selecionados neste grande ciclo de seleção massal. Foram constatadas diferenças altamente significativas, entre os clones avaliados, para as variáveis: produção, número de vassouras vegetativas, número de vassouras de almofada floral e número total de vassouras, porcentagem de frutos com vassoura de bruxa e porcentagem de frutos com podridão parda. Diferentes clones tiveram diferentes evoluções para essas características com o aumento da idade, e houve diferenças na adaptação aos ambientes. Entre as variedades atualmente recomendadas pela Ceplac para plantio comercial, as com melhor produção foram: FA 13, SJ 02, CCN 51, PS 1319, CEPEC 2002, CCN 10 e Vencedora 20. CCN 51, SJ 02 e FA 13 tiveram médias de produção significativamente superiores à da variedade PS 1319. Também produziram significativamente mais que a variedade PS 1319 os clones PS 5785, VT 05, RLF 1938, VT 10, CSG 70, FL 89, SL 06, BN 34 e FL 76.
\end{abstract}

Palavras-chave: Melhoramento genético do cacaueiro, resistência à vassoura de bruxa, resistência à podridão parda, Theobroma cacao.

Evaluation of cocoa clones as to the productivity and incidence of witches'

broom and black pod. It was evaluated 179 cocoa clones in an incomplete block design, in 79 locations, for a total period of 11 years. Most of these clones derive from a selection process for resistance and productivity conducted throughout the entire cocoa region of Bahia, and the apparently most promising among those selected in this great mass selection cycle were here chosen. Highly significant differences were found among the evaluated clones for the variables: production, number of vegetative brooms, number of floral cushion brooms and total number of brooms, percentage of fruits with witches' broom and percentage of fruits with black pod. Different clones had different evolutions for these characteristics with the increasing in age, and there were differences in adaptation for different environments. Among the varieties currently recommended by Ceplac for commercial planting, those with the best production were: FA 13, SJ 02, CCN 51, PS 1319, CEPEC 2002, CCN 10 and Vencedora 20. CCN 51, SJ 02 and FA 13 had production averages significantly higher than the variety PS 1319 . The clones: PS 5785, VT 05, RLF 1938, VT 10, CSG 70, FL 89, SL 06, BN 34 and FL 76 also produced significantly more than the PS 1319 variety.

Key words: Cacao genetic improvement, Resistance to witches' broom, Resistance to black pod, Theobroma cacao. 


\section{Introdução}

A chegada do agente causal da vassoura de bruxa na Bahia - a doença foi inicialmente descrita em 1895, no Suriname, durante os trinta anos seguintes foi registrada em todas as regiões produtoras próximas à Bacia Amazônica, e, em um segundo ciclo de expansão, quase 100 anos depois, é registrada no Panamá, em 1978, e, em 1989, na Bahia (Pereira, 1996), é elemento determinante na subsequente redução da produção nacional; e aciona dois grandes processos de melhoramento genético, a princípio distintos, e depois amalgamados em um grande programa de melhoramento que é conduzido pelo Centro de Pesquisa do Cacau (Cepec), da Comissão Executiva do Plano da Lavoura Cacaueira (Ceplac).

O primeiro destes é um amplo processo de seleção recorrente para produtividade e ampliação do nível e da durabilidade da resistência à vassoura de bruxa e outras doenças, pela associação de diferentes genes ligados a estes caracteres (Lopes et al., 2011; Benjamim et al., 2016; Pimenta Neto et al., 2018; Silva et al., 2010; Rodrigues, Pires \& luz, 2020; Yamada et al., 2014).

Este processo de seleção recorrente tem como fundamentação básica, em respeito à vassoura de bruxa, a existência de um grande número de diferentes fontes de resistência, com larga distinção em relação às médias gerais da espécie para vassouras na copa, almofadas florais e frutos, ampla diversidade entre elas (Pires, 2003), e ocorrência de diferentes genes de resistência (Albuquerque et al., 2010; Paim et al., 2006; Pires et al., 2012). Tem, ainda, como fundamentos o potencial de evolução do agente causal da doença e os riscos de se basear a resistência em uma única fonte, já em 2002, foi identificada a redução da resistência de descendentes de Scavina, a mais tradicional fonte de resistência à vassoura de bruxa (Bartley, 1994), e captado um processo de evolução do patógeno, que ocorreu concomitantemente com a intensificação de plantio de variedades com base de resistência do Scavina (Pires, 2003; Pires et al., 2012; Gramacho et al., 2012). Por fim, fundamenta-se, ainda, na comprovação da ampliação do nível e da durabilidade de resistência com a associação de diferentes genes, em áreas com evolução do patógeno, foi possível observar, quando da perda de efeito significativo da herança de Scavina atuando individualmente, a simultânea preservação deste efeito significativo com a associação com outros genes de resistência (Pires et al., 2009).

Esta linha de trabalho levou ao estabelecimento de ensaios para seleção recorrente com aproximadamente 1000 progênies ao todo, e ensaios regionais para a avaliação de um total aproximado de 1000 clones. Sua seleção produzirá as novas gerações de variedades comerciais.

O outro grande processo de melhoramento genético conduzido na região foi uma seleção massal que se desenrolou com a participação de centenas de agricultores, trabalhadores rurais e funcionários da Ceplac, em centenas de propriedades rurais. Neste processo foram selecionadas plantas que se mostravam produtivas e sem, ou com poucos sintomas de vassoura de bruxa, em áreas fortemente contaminadas. Estas plantas foram clonadas, intercambiadas entre os agricultores, várias trazidas ao Cepec, muitas avaliadas como clone. São, via de regra, plantas selecionadas em áreas com antigas variedades hibridas distribuídas pela Ceplac. E a avaliação de 179 destes clones, pré-selecionados como os de melhores potenciais, é o tema deste trabalho.

\section{Material e Métodos}

Foram avaliados 179 clones cultivados em 79 fazendas da Região Cacaueira da Bahia, em um período de 11 anos, em um sistema de blocos incompletos, com cada clone avaliado em parte das fazendas e, muitos, em parte dos anos. A grande maioria dos clones avaliados deriva de um processo de seleção massal, para resistência à vassoura de bruxa e produtividade, conduzido por toda a região cacaueira da Bahia; e o estabelecimento do experimento foi feito tomando ao acaso 10 plantas de cada clone por fazenda. Tais clones já estavam estabelecidos, e foram escolhidos os genótipos mais promissores dentre os resultantes deste amplo ciclo de seleção massal.

Os primeiros ensaios desta rede de avaliação foram estabelecidos em 2004, em cinco locais em propriedades do grupo M. Libânio, em Gandu, Bahia, sendo depois a rede expandida para outros 13 municípios: Ibicaraí, Juçari, Arataca, Barro Preto, Itabuna, Ilhéus, Camacan, Santa Luzia, São José da 
Vitória, Itajuípe, Buerarema, Itapitanga e Uruçuca. A obtenção de dados foi finalizada no primeiro semestre de 2015.

Foram verificadas as datas de enxertia das plantas a serem avaliadas e obtidos dados mensais por planta do número de frutos sadios, com vassoura de bruxa, com podridão parda, mumificados e inaproveitáveis por outras razões; do número de vassouras vegetativas e do número de vassouras de almofada floral. Periodicamente, foram tomadas amostras de frutos para a determinação do peso médio de sementes úmidas por fruto, sendo este usado para a conversão do número de frutos produzidos em produção estimada, com o uso da constante 0,38 para a transformação do peso úmido de sementes por fruto em peso seco por fruto (Pires, 2003).

Para as análises dos dados de produção e de ocorrência de doenças foi usado o princípio de blocos ao caso, com as fontes de variação: idade da planta, período (safra e entressafra), ano de avaliação, fazenda ou área e clone, em um modelo fixo, por PROC GLM, SAS (SAS Institute INC., 1988).

\section{Resultados e Discussão}

Foram observados, com as fontes de variação: idade da planta, período (safra e entressafra), ano de avaliação, fazenda e clone, efeitos altamente significativos para produção (estimada pelo produto do número de frutos sadios pelo peso médio de sementes secas por fruto), número de vassouras vegetativas, número de vassouras de almofada floral e número total de vassoura; porcentagem de frutos com vassoura de bruxa e porcentagem de frutos com podridão parda (dados não apresentados).

Também foram altamente significativas as interações clone $\mathrm{x}$ idade, o que significa que diferentes clones tiveram diferentes evoluções para estas características com o aumento da idade. Como esperado, o mesmo ocorre para a interação clone $\mathrm{x}$ período, de forma que há clones com proporções diferentes para a produção na safra e no temporão e também com proporções diferentes para perda de fruto por doenças, e quantidade de vassouras nestes períodos.

Também as interações clone $\mathrm{x}$ ano e clone $\mathrm{x}$ fazenda foram altamente significativas para todas as variáveis, indicando diferenças na adaptação dos clones para produção e níveis de doença em diferentes ambientes - fazendas e anos. A rede de ensaios contemplou grande diferenças de ambientes, com a maior parte dos ambientes em condições de cultivo não apropriadas, de forma que a seleção para melhores médias de produtividade, aquí, beneficia os genótipos com maiores estabilidades de produção.

As diferenças entre as médias gerais de todos os genótipos em todas as fazendas por todos os anos, na safra (setembro a fevereiro) e no temporão (março a agosto), apesar de significativas, foram numericamente pequenas: 34,05 e 35,00 arrobas, para mil plantas, 3,52 e 3,83 vassouras vegetativas por planta, 7,87 e 9,10 vassouras de almofada floral, para os períodos de safra e temporão, respectivamente. As proporções de perda de frutos foram de $11,45 \%$ e $9,56 \%$ para vassoura de bruxa e $8,88 \%$ e $7,53 \%$ para podridão parda, também respectivamente para safra e temporão (dados não apresentados).

Na Tabela 1 são apresentados os valores médios, conforme a idade e o ano, para o total por planta por semestre (período) para as características em estudo, a exceção de produção, cujas médias apresentadas são para o total de mil plantas, por ano, em arrobas. São relacionadas as médias observadas e as corrigidas pelo princípio de blocos incompletos para produção (Lsmeans, PROC GLM, SAS, SAS Institute INC., 1988) e somente as médias corrigidas para as demais características. Para comparações entre médias, são também apresentadas as Diferenças Mínimas Significativas (DMS), para 5\% de probabilidade de erro, pelo teste de Tukey. Como os números de repetições por célula em análise (idade ou ano) são diferentes, as comparações deveriam ser individuais, por teste de $\mathrm{T}$, com a consideração dos números de repetições específicos das duas médias comparadas, mas as tabelas para a apresentação dos resultados das comparações uma a uma seriam muito grandes, de modo que se usou o subterfugio de calcular a Diferença Mínima Significativa a partir da média harmônica do número de repetição para as células e usá-lo nas comparações de qualquer combinação entre duas médias, como um valor aproximado para a análise das distinções.

A produção contabilizada parece atingir um pico com a idade de sete anos e depois decrescer (Tabela 1 - Produção por idade, média não corrigida). Esta 
Tabela 1 - Médias para idade e o ano, corrigidas, para o total por planta por semestre (período) para vassouras vegetativas (VV), de almofada (VA), totais (VT), porcentagem de frutos com vassoura (PFVB), e com podridão parda (PFPP); produções médias anuais estimadas em arrobas por mil plantas, não corrigida (Prodncor) e corrigidas (Prod) e Diferenças Mínimas Significativas (DMS)

\begin{tabular}{|c|c|c|c|c|c|c|c|}
\hline Idade & Prodncor & Prod & VV & VA & VT & PFVB & PFPP \\
\hline 3 & 34,43 & 30,68 & 2,85 & 6,04 & 8,89 & 14,23 & 6,38 \\
\hline 4 & 45,50 & 42,95 & 2,93 & 5,76 & 8,69 & 9,82 & 6,00 \\
\hline 5 & 56,26 & 53,54 & 2,42 & 5,00 & 7,42 & 10,16 & 5,52 \\
\hline 6 & 63,61 & 61,84 & 3,03 & 6,06 & 9,09 & 9,73 & 5,35 \\
\hline 7 & 68,61 & 66,94 & 4,07 & 7,23 & 11,30 & 9,61 & 6,40 \\
\hline 8 & 61,37 & 71,36 & 4,65 & 7,60 & 12,25 & 10,29 & 7,53 \\
\hline 9 & 56,26 & 73,12 & 4,76 & 7,28 & 12,04 & 10,97 & 7,10 \\
\hline 10 & 62,12 & 79,44 & 4,73 & 8,32 & 13,05 & 11,56 & 4,86 \\
\hline 11 & 61,68 & 82,03 & 5,85 & 7,95 & 13,80 & 10,91 & 5,26 \\
\hline 12 & 53,21 & 80,36 & 7,02 & 11,89 & 18,91 & 12,38 & 5,18 \\
\hline 13 & 55,71 & 85,20 & 3,74 & 11,51 & 15,24 & 11,33 & 2,71 \\
\hline 14 & 61,17 & 86,58 & 2,43 & 10,53 & 12,96 & 8,45 & 3,14 \\
\hline 15 & 49,33 & 83,57 & $-0,79$ & 15,17 & 14,39 & 7,18 & 9,71 \\
\hline DMS & & 7,54 & 1,01 & 1,78 & 2,38 & 2,17 & 2,14 \\
\hline Ano & Prodncor & Prod & VV & VA & VT & PFVB & PFPP \\
\hline 2004 & 122,17 & 135,97 & 5,19 & 9,23 & 14,42 & 9,19 & $-0,08$ \\
\hline 2005 & 98,86 & 106,98 & 5,10 & 7,74 & 12,84 & 7,76 & 0,92 \\
\hline 2006 & 83,91 & 85,39 & 4,67 & 8,09 & 12,76 & 11,74 & 1,00 \\
\hline 2007 & 59,98 & 71,61 & 3,92 & 9,13 & 13,05 & 16,44 & 2,32 \\
\hline 2008 & 54,83 & 60,60 & 4,86 & 7,89 & 12,75 & 9,19 & $-1,07$ \\
\hline 2009 & 52,70 & 53,34 & 4,73 & 8,90 & 13,63 & 12,28 & 1,18 \\
\hline 2010 & 78,59 & 76,86 & 1,17 & 5,46 & 6,62 & 8,56 & 8,11 \\
\hline 2011 & 51,22 & 43,48 & 2,17 & 9,73 & 11,90 & 11,20 & 15,39 \\
\hline 2012 & 54,49 & 41,73 & 2,11 & 8,55 & 10,66 & 8,38 & 12,84 \\
\hline 2013 & 38,39 & 19,82 & 4,55 & 11,24 & 15,79 & 10,08 & 17,37 \\
\hline 2014 & 88,69 & 63,73 & 1,89 & 7,41 & 9,30 & 10,77 & 5,60 \\
\hline DMS & & 8,74 & 1,17 & 2,06 & 2,75 & 2,40 & 2,37 \\
\hline
\end{tabular}

primeiro ano e não se diferencia mais estatisticamente a partir daí, de forma que parece ser esta a tendência geral (Tabela 1 - Produção por idade, média corrigida).

Não houve qualquer tendência de aumento do número de vassouras ou de perda de frutos por vassoura de bruxa no decorrer dos anos, e as alterações parecem ser casuais, provavelmente devidas a variações do clima. Portanto, não há qualquer indicativo de tendência geral de perda de resistência. Para podridão parda houve uma concentração de anos com maior incidência entre 2011 e 2013.

Há uma clara tendência de aumento de vassouras de almofada floral e total de vassouras com a idade, mas isto pode se dever ao aumento de porte das plantas. E não há tendência de aumento de perda de frutos quer por vassoura de bruxa, quer por podridão parda.

As médias de fazenda ou local do ensaio variaram de 15,15 a 202,77 arrobas por mil plantas ano, quando corrigidas para clone, ano e idade; com uma DMS de 26,77 para Tukey, a 5\% de probabilidade para o erro na afirmação de diferenças entre médias constatação errônea poderia prevalecer se as plantas fossem todas da mesma idade na rede de avaliação, e não pudéssemos extrair outro elemento primordial nesta média, que são as condições do ano (foram tomadas plantas já em cultivo para os ensaios e, portanto, de diferentes idades). Pelas médias de ano constata-se que houve piora nas condições de cultivo no decorrer dos anos (Tabela 1 - Produção por ano, média não corrigida e corrigida), quando cresce a proporção de plantas com maior idade, lembrando-se aqui que os ensaios seguiram as condições de manejo aplicadas, de forma geral, em cada propriedade. Assim, corrigida para as demais fontes de variação, a produção se mostra crescente até o décimo, décimo (novamente calculado a partir da média harmônica do numero de repetições de fazenda ou local). Para vassouras vegetativas as médias corrigidas variaram de $-1,44$ a 23,11 por planta por semestre, com uma DMS de 3,57 (a correção pode gerar números negativos, neste caso, por exemplo, para uma fazenda que teve muito pouca incidência de vassoura de bruxa e englobava genótipos e/ou anos com altas médias de vassoura de bruxa). Para vassouras de almofadas florais ocorreram médias de $-5,01$ a 45,46, com uma DMS de 6,32. Para vassouras totais as médias corrigidas estiveram entre $-3,13$ a 68,57 , e a DMS foi de 8,43 . Já para a perda de frutos, as médias com vassoura de bruxa foram de $-7,12$ a $35,23 \%$, com 
uma DMS de 7,52, e com podridão parda, de $-6,61$ a $21,00 \%$, com uma DMS de 7,43 (dados não apresentados).

Estas médias corrigidas representam as médias proporcionais esperadas se cada fazenda tivesse todos os clones avaliados, em todos os anos, com as mesmas idades. E mostram uma variação muito grande de condições de cultivo entre as diversas propriedades, o que, a princípio, é importante quando da busca de genótipos de elevada estabilidade de produção.

Quanto à produção, foram tomadas como referências as cinco primeiras variedades indicadas para plantio comercial na Bahia: Cepec 42, TSH 1188, EET 397, TSH 516 e TSH 565; e na Tabela 2 são listados todos os clones avaliados em pelo menos duas fazendas, cujas produções médias suplantaram em valor numérico a produção da referência com menor média, o TSH 565. As médias destes clones são comparadas, pelo teste de $\mathrm{T}$, às das duas variedades comerciais primeiramente indicadas que mostraram as maiores produções: Cepec 42 e TSH 1188; e às de PS 1319 e CSG 70 - a apresentação dos resultados de todas as comparações resultaria em uma Tabela muito grande, e o uso de uma DMS a partir da média harmônica do número de repetições, de modo análogo ao feito anteriormente para ano e idade, geraria, neste caso, maiores distorções, por haver proporcionalmente mais diferenças para o número de repetições de clones do que havia para repetições de anos e de idades.

Nas análises das diferenças entre as produções, existe uma fonte de variação não computada para o cálculo das probabilidades de erro, que é o erro associado à transformação do número de frutos contabilizados em produção, pelo produto do número de frutos pelo peso médio de sementes úmidas por fruto e por 0,38 , sendo este valor para a conversão de peso úmido em peso seco. A este respeito, tem-se que foram tomados, em média, 40 frutos por clone para a maioria dos genótipos e um número muito maior para os clones dos primeiros ensaios em Gandu; e para uma amostragem análoga a esta, conduzida na Coleção de Germoplasma do CEPEC, foi observado um coeficiente de correlação (Pearson) de 0,97, entre as médias obtidas para a produção em semente úmida e os valores resultantes do produto do numero de frutos sadios pelo peso de sementes úmidas por fruto, calculado a partir das amostras (Pires, 2003). E a correlação (Pearson) encontrada entre o peso de sementes úmidas e o peso de sementes secas por frutos foi de 0,95, também na Coleção de Germoplasma, em que se espera uma correlação menor que para o caso dos clones aqui avaliados, pela maior diversidade genética (Pires, 2003). Assim, as probabilidades de erro apresentadas na Tabela 2 são aproximações, mas obtidas a partir de indicadores eficientes.

Atualmente são recomendadas pela Ceplac para plantio comercial as variedades: SJ 02, Cepec 2002 ou VB 1151, CCN 51, PS 1319, PH 16, CP 49, Cepec 2007 ou VB 681, Ipiranga 1, FA 13, Vencedora 20 ou Ven 20, PH 09, CCN 10, LP 06, PH 15 Salobrinho 3 ou SAL 3 e BJ 11. E neste estudo as variedades com melhor desempenho foram: FA 13, SJ 02, CCN 51, PS 1319, CEPEC 2002, CCN 10 e Vencedora 20, todas com médias significativamente superiores às das variedades TSH 1188 e Cepec 42 e superiores ou não distintas da média da PS 1319. No polo oposto estiveram as variedades PH 09, CEPEC 2007 e PH 16, com médias não diferentes da do clone TSH 1188 e inferiores às do CEPEC 42 e do PS 1319 (Tabela 2).

As variedades comerciais CCN 51, SJ 02 e FA 13 tiveram médias significativamente superiores à da variedade PS 1319, que tem sido a variedade preferida de muitos agricultores. Neste ponto, tendo-se em conta que um dos objetivos deste artigo é ajudar aos agricultores nas escolhas das variedades a serem cultivadas em suas propriedades, por esta apresentação do desempenho comparativo para caracteres que não são facilmente observáveis, como são o porte, tamanho de frutos e sementes, arquitetura da planta, etc., fazse importante uma consideração sobre probabilidade. Assim, por exemplo, pode-se dizer, com uma probabilidade de erro menor que cinco em 100 (a probabilidade calculada foi $1,09 \%$ ) que o CCN 51 produziu mais que o PS 1319 (Tabela 2), e que se repetido o experimento centenas de vezes, o CCN 51 produziria mais que o PS 1319 em mais de 95 experimentos em cada 100. Por outro lado, o CCN 51 produziu $6,8 \%$ a mais que o PS 1319 , e não podemos dizer que o primeiro produz $6,8 \%$ a mais que o segundo. Ou seja, o teste estatístico diz se uma média é diferente da outra, e não a dimensão exata da diferença.

Ainda, as comparações são válidas para o conjunto de ambientes considerados, que é muito amplo, mas 
Tabela 2 - Médias de produção em arrobas por mil plantas dos clones avaliados em pelo menos duas fazendas cujas produções médias suplantaram em valor numérico a produção do TSH 565, comparadas, pelo teste de T, às dos clones: Cepec 42, TSH 1188, PS 1319 e CSG 70

\begin{tabular}{|c|c|c|c|c|c|c|}
\hline Clone & NroFaz & Prod & TSH1188 & СЕРЕC42 & PS1319 & CSG70 \\
\hline PS5784 & 2 & 225,72 & $* *$ & $* *$ & $* *$ & $* *$ \\
\hline VT05 & 3 & 207,63 & $* *$ & $* *$ & $* *$ & $* *$ \\
\hline RLF1938 & 2 & 184,55 & $* *$ & $* *$ & $* *$ & $* *$ \\
\hline VT10 & 3 & 158,18 & $* *$ & $* *$ & $* *$ & $*$ \\
\hline FA13 & 6 & 150,16 & $* *$ & $* *$ & $* *$ & ns \\
\hline CSG70 & 6 & 142,70 & $* *$ & $* *$ & $* *$ & . \\
\hline FL89 & 2 & 120,44 & $* *$ & $* *$ & $* *$ & $*$ \\
\hline SJ02 & 25 & 116,43 & $* *$ & $* *$ & $* *$ & $* *$ \\
\hline SL06 & 3 & 112,14 & $* *$ & $* *$ & $*$ & $* *$ \\
\hline BN34 & 10 & 108,82 & $* *$ & $* *$ & $* *$ & $* *$ \\
\hline FL76 & 3 & 108,44 & $* *$ & $* *$ & $*$ & $* *$ \\
\hline CCN51 & 55 & 99,34 & $* *$ & $* *$ & $*$ & $* *$ \\
\hline MCB09 & 4 & 96,44 & $* *$ & $* *$ & ns & $* *$ \\
\hline FG110 & 4 & 93,69 & $* *$ & $* *$ & ns & $* *$ \\
\hline PS1319 & 21 & 93,02 & $* *$ & $* *$ & . & $* *$ \\
\hline PS1910 & 2 & 93,00 & $* *$ & $*$ & ns & $* *$ \\
\hline CEPEC2002 & 28 & 91,95 & $* *$ & $* *$ & ns & $* *$ \\
\hline CCN10 & 32 & 91,25 & $* *$ & $* *$ & ns & $* *$ \\
\hline VEN20 & 7 & 90,85 & $* *$ & $* *$ & ns & $* *$ \\
\hline PS1030 & 2 & 90,82 & $* *$ & ns & ns & $* *$ \\
\hline PH114 & 5 & 88,75 & $* *$ & $*$ & ns & $* *$ \\
\hline FSH42 & 2 & 86,41 & $* *$ & ns & ns & $* *$ \\
\hline JVP01 & 3 & 86,11 & $* *$ & $*$ & ns & $* *$ \\
\hline FL78 & 4 & 85,06 & $* *$ & $* *$ & ns & $* *$ \\
\hline RVID08 & 9 & 81,54 & $* *$ & $*$ & $* *$ & $* *$ \\
\hline CAMACAN1 & 7 & 80,56 & $* *$ & ns & $* *$ & $* *$ \\
\hline CP49 & 3 & 80,15 & ns & ns & ns & $* *$ \\
\hline CAE35 & 6 & 79,67 & $* *$ & ns & $* *$ & $* *$ \\
\hline AL50 & 4 & 78,24 & $*$ & ns & $*$ & $* *$ \\
\hline SC75 & 4 & 76,98 & $*$ & ns & $* *$ & $* *$ \\
\hline CEPEC2004 & 4 & 76,88 & $*$ & ns & $* *$ & $* *$ \\
\hline PH92 & 6 & 76,17 & ns & ns & $* *$ & $* *$ \\
\hline BJ11 & 12 & 75,35 & $* *$ & ns & $* *$ & $* *$ \\
\hline PH15 & 15 & 75,08 & $* *$ & ns & $* *$ & $* *$ \\
\hline SJ104 & 3 & 74,76 & ns & ns & $* *$ & $* *$ \\
\hline STACRUZ & 4 & 73,66 & ns & ns & $*$ & $* *$ \\
\hline SAL03 & 11 & 73,36 & * & ns & $* *$ & $* *$ \\
\hline $\mathrm{T} 10$ & 2 & 72,92 & ns & ns & $* *$ & $* *$ \\
\hline CEPEC42 & 19 & 72,75 & $* *$ & . & $* *$ & $* *$ \\
\hline MAR051 & 4 & 72,74 & ns & ns & $* *$ & $* *$ \\
\hline MAC01 & 5 & 72,62 & ns & ns & $* *$ & $* *$ \\
\hline PS1.6 & 2 & 72,03 & ns & $\mathrm{ns}$ & $* *$ & $* *$ \\
\hline LP06 & 11 & 71,98 & ns & ns & $* *$ & $* *$ \\
\hline PAIN9324 & 4 & 71,48 & ns & ns & $* *$ & $* *$ \\
\hline M05 & 3 & 70,59 & ns & ns & $* *$ & $* *$ \\
\hline PH129 & 5 & 70,36 & ns & ns & $* *$ & $* *$ \\
\hline FT500 & 3 & 69,93 & ns & $\mathrm{ns}$ & $* *$ & $* *$ \\
\hline
\end{tabular}


Continuação da Tabela 2.

\begin{tabular}{|c|c|c|c|c|c|c|}
\hline VB990 & 2 & 69,69 & $\mathrm{~ns}$ & $\mathrm{~ns}$ & $*$ & $* *$ \\
\hline BP41 & 3 & 69,36 & ns & ns & $* *$ & $* *$ \\
\hline FSU01 & 2 & 68,87 & ns & ns & $* *$ & $* *$ \\
\hline $\mathrm{T} 11$ & 2 & 66,77 & ns & ns & $* *$ & $* *$ \\
\hline ST01 & 4 & 66,54 & ns & ns & $* *$ & $* *$ \\
\hline CEPEC2006 & 2 & 65,82 & $\mathrm{~ns}$ & $\mathrm{~ns}$ & $*$ & $* *$ \\
\hline FB206 & 14 & 65,75 & $\mathrm{~ns}$ & ns & $* *$ & $* *$ \\
\hline TSH1188 & 44 & 65,11 & . & $* *$ & $* *$ & $* *$ \\
\hline IPIRANGA & 14 & 64,80 & ns & ns & $* *$ & $* *$ \\
\hline HW25 & 5 & 64,78 & ns & ns & $* *$ & $* *$ \\
\hline CEPEC2005 & 3 & 64,29 & $\mathrm{~ns}$ & ns & $* *$ & $* *$ \\
\hline EQX107 & 3 & 64,14 & ns & ns & $* *$ & $* *$ \\
\hline FO30.9 & 2 & 61,46 & $\mathrm{~ns}$ & $\mathrm{~ns}$ & $* *$ & $* *$ \\
\hline PH09 & 11 & 61,03 & ns & $*$ & $* *$ & $* *$ \\
\hline CCN16 & 3 & 60,93 & $\mathrm{~ns}$ & ns & $* *$ & $* *$ \\
\hline CEPEC2007 & 6 & 60,70 & ns & $* *$ & $* *$ & $* *$ \\
\hline CA1.4 & 19 & 60,36 & $\mathrm{~ns}$ & $* *$ & $* *$ & $* *$ \\
\hline EET397 & 22 & 59,17 & $*$ & $* *$ & $* *$ & $* *$ \\
\hline SL70 & 3 & 58,01 & ns & ns & $* *$ & $* *$ \\
\hline SP50 & 4 & 57,96 & ns & $* *$ & $* *$ & $* *$ \\
\hline TSH516 & 20 & 57,87 & $* *$ & $* *$ & $* *$ & $* *$ \\
\hline TSA792 & 15 & 57,80 & $*$ & $* *$ & $* *$ & $* *$ \\
\hline M20 & 2 & 56,98 & $\mathrm{~ns}$ & $*$ & $* *$ & $* *$ \\
\hline PH16 & 33 & 56,91 & $\mathrm{~ns}$ & $* *$ & $* *$ & $* *$ \\
\hline RVID05 & 3 & 56,53 & ns & $* *$ & $* *$ & $* *$ \\
\hline TSH565 & 21 & 56,40 & $* *$ & $* *$ & $* *$ & $* *$ \\
\hline
\end{tabular}

ns - diferença não significativa; * significativa para $\mathrm{p}<0,05 \mathrm{e}^{* *}$ significativa para $\mathrm{p}<0,01$

ambientes específicos alterariam as proporções, conforme já discutido - interações clone x ano e clone $\mathrm{x}$ fazenda altamente significativas, indicando diferenças na adaptação dos clones estudados para os diferentes ambientes.

Além do CCN 51, do SJ 02 e do FA 13, também produziram significativamente mais que o PS 1319 os clones PS 5785, VT 05, RLF 1938, VT 10, CSG 70, FL 89, SL 06, BN 34 e FL 76; o que mostra que o grande processo de seleção massal conduzido na Bahia ainda pode resultar na indicação de novas variedades para cultivo comercial. Estes genótipos de maior produção foram repetidos em novos ensaios regionais, que estão em andamento, e vários, assim como as melhores variedades comerciais, foram incluídos como progenitores nos programas de seleção recorrente conduzidos no Cepec (Rodrigues, Pires \& luz, 2020). Ainda, dentre os clones presentes em apenas uma propriedade, alguns tiveram médias estimadas superiores a 100 arrobas por mil plantas e estão sendo avaliados nos novos ensaios: NSV 04, MAR 028, NSV 10, OCC 01.

Sobre a metodologia para a avaliação, a estrutura experimental permitiu a constatação de diferenças estatísticas entre médias com diferenças numéricas não muito grandes, mesmo para o caso de clones com poucas repetições de locais. Por exemplo, o clone VT 10 , avaliado em três fazendas, diferiu significativamente do CSG 70, avaliado em seis, com uma média $11 \%$ maior (Tabela 2).

Mas, outra consideração acerca destes resultados parece necessária: a possibilidade de desvios nas correções de médias pelo princípio de Blocos Incompletos, quando ocorrem interações significativas. Por exemplo, o clone referência Cepec 42 produziu, em valores não corrigidos para a média das 19 fazendas onde foi avaliado, 74,08 arrobas por mil plantas (não apresentado), que foram corrigidas para 72,75 arrobas (Lsmeans, PROC GLM, SAS, SAS Institute INC., 1988). Já o clone BN 34, 
reconhecidamente produtivo, teve uma média de produção de 62,20 arrobas (não apresentado), que foi corrigida para 108,82 arrobas, sendo esta larga correção devida principalmente ao fato que as plantas de BN 34 tiveram dados computados também quando eram muito novas. Esta correção para o BN 34 foi em um montante proporcional ao que se espera, em média, para o aumento de produção com a idade, de forma que a diferença de sua média em relação à do Cepec 42 pode estar superestimada, se o BN 34 for mais precoce que o Cepec 42, ou subestimada, se for o contrário (na verdade o BN 34 parece ter produção precoce). Por outro lado, não há nada que sugira que os clones listados como de boa produção, de modo geral, não o sejam.

Para a incidência de vassoura de bruxa, as diferenças entre os clones avaliados, apesar de altamente significativas, não foram muito grandes. E tem-se que, as primeiras variedades clonais recomendadas para plantio comercial descendem do clone Scavina 6, coletado nos primeiros trabalhos voltados a busca de resistência às doenças do cacaueiro, na década de 1930, no Peru (Pound, 1938). Este mesmo clone e, certamente, alguns descendentes foram utilizados como progenitores de variedades híbridas distribuídas pela Ceplac, e as seleções em fazendas devem, em sua maioria ou totalidade, serem descendentes de Scavina. O clone Scavina 6 tem se mostrado como portador de dois alelos maiores para resistência, cujos efeitos, em diferentes localidades da região cacaueira da Bahia, vêm sendo quebrados quando um alelo atua individualmente, mas preservado quando em associação com outro gene ou alelo de resistência (Pires, et al., 2009; Pires et al., 2012; Gramacho et al., 2012; Pimenta Neto et al., 2018). E mesmo sem quebra de resistência, descendentes de Scavina, apesar de diferirem muito de materiais tidos como não resistentes em termos de perda de frutos por vassoura de bruxa em níveis médios de pressão de inóculo, diferem pouco quando sob alta pressão de inóculo (Pires, 2003). Já uma herança de resistência reconhecidamente diferente da de Scavina ocorre nos clones da série CCN (Pires et al., 2012), provavelmente derivada de um clone do Equador de nome Canelos.

As médias de incidência de vassoura de bruxa dos clones anteriormente listados são apresentadas na Tabela 3, e, novamente, para evitar tabelas muito grandes, foi calculada a Diferença Mínima Significativa a partir da média harmônica do número de repetições. Isto para uma comparação aproximada entre estas médias, mas as DMS são fortemente superestimadas para comparações entre clones avaliados em muitas fazendas e subestimados para comparações entre clones avaliados em poucas.

Para a soma das vassouras vegetativas e de almofada floral (VT), os melhores desempenhos entre os clones de maior produção (produção maior ou não diferente da do PS 1319) foram os do PH 114, CCN 10, CSG 70, BN 34, CCN 51, RLF 1938, Cepec 2002, FL 76, Vencedora 20 (VEN 20), SJ 02 e PS 1030. Os de maiores valores numéricos para a média do total de vassouras entre os mais produtivos foram: SL 06, JVP 01, VT 10, MCB 09, PS 1319 e PS 1910.

Das primeiras variedades indicadas, todas tiveram mais de 10 vassouras por planta por semestre, sendo os piores resultados os do EET 397 e do TSH 516 e o melhor o do Cepec 42.

Independente da produção as menores incidências foram as nos clones: PH 114, SL 70, MAC 01, FB 206, ST 01, Santa Cruz, e FSU 01. As maiores foram as nos clones: SL 06, FT 500, EQX 107, EET 397, CA 1.4, JVP 01 e TSH 516.

No geral, houve uma variação do total de vassouras por planta/semestre de $-0,22$ a 27,76 , sendo a maior parte devida às diferenças quanto ao número de vassouras de almofada floral: de $-0,37$ a 23,45 vassouras/planta/semestre. Uma variação muito maior já foi citada para as médias de fazendas: de $-5,01$ a 45,46 vassouras de almofada floral por planta/semestre. E registra-se que os processos de redução do padrão de resistência de descendentes de Scavina por mudança populacional do fungo parecem ocorrer principalmente com vassouras de almofadas florais (Pires, 2003; Pires et al., 2012).

Os melhores desempenhos para a variável número de vassouras de almofada floral entre os clones de produção maior ou não diferente da do PS 1319 foram os do PH 114, CSG 70, RLF 1938, BN 34, CCN 10, SJ 02, CCN 51, Vencedora 20, Cepec 2002, PS 1030, FL 76 e FA 13. Os clones com maiores números de vassouras de almofada floral entre os mais produtivos foram: SL 06, JVP 01, VT 10, MCB 09, FG 110, PS 1910, PS 1319 e FL 789.

Novamente as primeiras variedades indicadas, a exceção do Cepec 42, estiveram entre os clones com 
Tabela 3 - Médias corrigidas de clones para o total por planta por semestre (período) para vassouras vegetativas (VV), de almofada (VA), totais (VT), porcentagem de frutos com vassoura (PFVB), e com podridão parda (PFPP); produções médias anuais corrigidas em arrobas por mil plantas (Prod) e Diferenças Mínimas Significativas (DMS)

\begin{tabular}{|c|c|c|c|c|c|c|c|}
\hline Clone & NroFaz & Prod & $\mathbf{V V}$ & VA & VT & PFVB & PFPP \\
\hline PS5784 & 2 & 225,72 & 3,61 & 7,57 & 11,18 & 8,86 & 9,08 \\
\hline VT05 & 3 & 207,63 & 3,43 & 7,56 & 10,99 & 7,40 & 5,23 \\
\hline RLF1938 & 2 & 184,55 & 3,39 & 4,15 & 7,54 & 5,80 & 3,55 \\
\hline VT10 & 3 & 158,18 & 4,23 & 11,13 & 15,36 & 15,00 & 6,42 \\
\hline FA13 & 6 & 150,16 & 3,79 & 6,57 & 10,36 & 8,00 & 2,23 \\
\hline CSG70 & 6 & 142,70 & 4,65 & 1,89 & 6,54 & 4,76 & 1,26 \\
\hline FL89 & 2 & 120,44 & 3,02 & 7,52 & 10,54 & 7,05 & $-1,38$ \\
\hline SJ02 & 25 & 116,43 & 4,55 & 4,70 & 9,25 & 7,18 & 2,35 \\
\hline SL06 & 3 & 112,14 & 4,31 & 23,45 & 27,76 & 2,66 & 2,47 \\
\hline BN34 & 10 & 108,82 & 2,53 & 4,20 & 6,72 & 9,37 & 0,97 \\
\hline FL76 & 3 & 108,44 & 2,04 & 6,56 & 8,60 & 7,42 & 2,89 \\
\hline CCN51 & 55 & 99,34 & 2,12 & 5,19 & 7,31 & 7,28 & 4,62 \\
\hline МCB09 & 4 & 96,44 & 3,79 & 10,60 & 14,39 & 20,70 & 6,49 \\
\hline FG110 & 4 & 93,69 & 1,94 & 8,77 & 10,71 & 6,72 & 3,67 \\
\hline PS1319 & 21 & 93,02 & 4,67 & 8,27 & 12,94 & 11,20 & 5,52 \\
\hline PS1910 & 2 & 93,00 & 3,86 & 8,45 & 12,31 & 12,16 & 4,06 \\
\hline CEPEC2002 & 28 & 91,95 & 2,34 & 6,16 & 8,50 & 10,03 & 6,27 \\
\hline CCN10 & 32 & 91,25 & 1,80 & 4,60 & 6,39 & 9,42 & 4,55 \\
\hline VEN20 & 7 & 90,85 & 2,63 & 6,04 & 8,67 & 7,96 & $-1,57$ \\
\hline PS1030 & 2 & 90,82 & 2,82 & 6,53 & 9,36 & 7,07 & 4,35 \\
\hline PH114 & 5 & 88,75 & 0,15 & $-0,37$ & $-0,22$ & 4,85 & 3,24 \\
\hline FSH42 & 2 & 86,41 & 2,83 & 7,53 & 10,35 & 7,58 & 0,16 \\
\hline JVP01 & 3 & 86,11 & 6,09 & 12,69 & 18,78 & 15,28 & 7,47 \\
\hline FL78 & 4 & 85,06 & 2,02 & 8,09 & 10,12 & 6,22 & $-3,08$ \\
\hline RVID08 & 9 & 81,54 & 3,15 & 8,01 & 11,16 & 10,45 & 8,24 \\
\hline CAMACAN1 & 7 & 80,56 & 2,71 & 8,95 & 11,66 & 6,58 & 2,23 \\
\hline CP49 & 3 & 80,15 & 3,51 & 7,46 & 10,98 & 17,98 & 21,55 \\
\hline CAE35 & 6 & 79,67 & 3,40 & 6,27 & 9,67 & 9,27 & 5,66 \\
\hline AL50 & 4 & 78,24 & 3,19 & 6,52 & 9,71 & 8,58 & 1,68 \\
\hline SC75 & 4 & 76,98 & 4,36 & 6,89 & 11,25 & 13,23 & 10,41 \\
\hline CEPEC2004 & 4 & 76,88 & 3,82 & 13,17 & 16,99 & 11,29 & 5,96 \\
\hline PH92 & 6 & 76,17 & 2,97 & 14,28 & 17,25 & 8,69 & 2,31 \\
\hline BJ11 & 12 & 75,35 & 2,62 & 5,97 & 8,60 & 12,99 & 4,65 \\
\hline PH15 & 15 & 75,08 & 3,06 & 6,50 & 9,56 & 9,18 & 4,62 \\
\hline SJ104 & 3 & 74,76 & 3,79 & 9,26 & 13,05 & 12,64 & 5,55 \\
\hline STACRUZ & 4 & 73,66 & 1,20 & 3,67 & 4,86 & 7,82 & 5,14 \\
\hline SAL03 & 11 & 73,36 & 2,31 & 4,43 & 6,73 & 11,99 & 6,83 \\
\hline $\mathrm{T} 10$ & 2 & 72,92 & 0,21 & 7,73 & 7,95 & 6,09 & 4,35 \\
\hline CEPEC42 & 19 & 72,75 & 3,56 & 6,54 & 10,10 & 14,16 & 4,80 \\
\hline MAR051 & 4 & 72,74 & 1,65 & 4,32 & 5,97 & 7,70 & 4,60 \\
\hline MAC01 & 5 & 72,62 & 0,54 & 2,56 & 3,10 & 2,62 & 2,25 \\
\hline PS1.6 & 2 & 72,03 & 3,05 & 4,64 & 7,69 & 9,85 & $-0,04$ \\
\hline LP06 & 11 & 71,98 & 5,99 & 8,33 & 14,32 & 10,28 & 3,11 \\
\hline PAIN9324 & 4 & 71,48 & 6,74 & 10,25 & 16,99 & 12,04 & 7,66 \\
\hline M05 & 3 & 70,59 & 2,27 & 6,32 & 8,58 & 7,96 & 4,08 \\
\hline PH129 & 5 & 70,36 & 3,94 & 7,59 & 11,53 & 10,48 & 7,19 \\
\hline FT500 & 3 & 69,93 & 11,08 & 12,14 & 23,21 & 15,17 & 4,42 \\
\hline VB990 & 2 & 69,69 & 2,90 & 7,59 & 10,49 & 9,51 & 5,22 \\
\hline BP41 & 3 & 69,36 & 2,11 & 3,52 & 5,63 & 7,43 & 11,13 \\
\hline FSU01 & 2 & 68,87 & 1,23 & 4,12 & 5,35 & 8,07 & 0,76 \\
\hline
\end{tabular}


Continuação da Tabela 3.

\begin{tabular}{|c|c|c|c|c|c|c|c|}
\hline $\mathrm{T} 11$ & 2 & 66,77 & 1,80 & 9,58 & 11,38 & 1,87 & 6,94 \\
\hline ST01 & 4 & 66,54 & 2,44 & 0,96 & 3,40 & 8,71 & $-2,70$ \\
\hline CEPEC2006 & 2 & 65,82 & 3,27 & 6,66 & 9,93 & 9,44 & 4,16 \\
\hline FB206 & 14 & 65,75 & 0,95 & 2,37 & 3,32 & 8,85 & 10,99 \\
\hline TSH1188 & 44 & 65,11 & 2,66 & 10,42 & 13,08 & 7,76 & 3,59 \\
\hline IPIRANGA & 14 & 64,80 & 3,14 & 6,36 & 9,50 & 8,50 & 5,28 \\
\hline HW25 & 5 & 64,78 & 2,33 & 6,32 & 8,65 & 7,21 & 3,22 \\
\hline CEPEC2005 & 3 & 64,29 & 3,89 & 8,95 & 12,83 & 9,04 & 8,02 \\
\hline EQX107 & 3 & 64,14 & 1,43 & 20,33 & 21,75 & 5,86 & 2,66 \\
\hline FO30.9 & 2 & 61,46 & 4,50 & 13,28 & 17,78 & 12,60 & 7,92 \\
\hline PH09 & 11 & 61,03 & 5,84 & 10,89 & 16,73 & 17,67 & 8,94 \\
\hline CCN16 & 3 & 60,93 & 2,51 & 6,96 & 9,48 & 11,71 & 10,59 \\
\hline CEPEC2007 & 6 & 60,70 & 2,23 & 4,11 & 6,34 & 4,50 & 4,08 \\
\hline CA1.4 & 19 & 60,36 & 3,41 & 16,07 & 19,48 & 14,69 & 3,46 \\
\hline EET397 & 22 & 59,17 & 4,90 & 15,11 & 20,01 & 15,79 & 6,08 \\
\hline SL70 & 3 & 58,01 & 2,56 & $-0,38$ & 2,18 & 6,84 & 8,13 \\
\hline SP50 & 4 & 57,96 & 2,46 & 4,17 & 6,64 & 5,55 & 1,47 \\
\hline TSH516 & 20 & 57,87 & 5,09 & 13,63 & 18,72 & 12,94 & 6,40 \\
\hline TSA792 & 15 & 57,80 & 2,77 & 8,30 & 11,07 & 12,00 & 8,53 \\
\hline M20 & 2 & 56,98 & 1,75 & 7,96 & 9,71 & 8,41 & 1,58 \\
\hline PH16 & 33 & 56,91 & 1,92 & 3,99 & 5,90 & 12,34 & 7,10 \\
\hline RVID05 & 3 & 56,53 & 2,05 & 6,46 & 8,51 & 7,82 & 6,90 \\
\hline TSH565 & 21 & 56,40 & 2,91 & 9,58 & 12,48 & 16,16 & 7,58 \\
\hline DMS & & & 3,63 & 7,33 & 9,55 & 8,87 & 8,72 \\
\hline
\end{tabular}

maiores números de vassoura, com o EET 397 e o TSH 516 apresentando, outra vez, os piores resultados para o grupo. E tendo este material comprovadamente mudado de patamar de resistência em alguns locais, com a evolução do patógeno (Pires, 2003; Pires et al., 2012), seu desempenho médio comparativamente inferior indica que isto deve ter ocorrido em vários locais. Tal mudança populacional do fungo foi, obviamente, resultado do cultivo em maior escala destas variedades, e um cultivo em grande escala ocorre hoje com o PS 1319, que também esteve entre as variedades mais afetadas pela vassoura.

Por outro lado, há clones certamente descendentes de Scavina com significativamente menos vassouras, e a preservação do padrão de resistências de alguns descendentes de Scavina, enquanto outros o perdem, foi observada quando da associação de Scavina com outras fontes de resistência (Pires et al., 2009), de forma que os clones de melhor desempenho devem ter genes ou alelos, de grandes ou pequenos efeitos, a mais ou diferentes dos que acompanham a herança de Scavina nestes materiais menos resistentes.
No geral, as menores incidências foram as nos clones: SL 70, PH 114, ST 01, CSG 70, FB 206, MAC 01, BP 41, Santa Cruz, e PH 16. As maiores foram as de: SL 06, EQX 107, FB 206, CA 1.4, EET 397, PH 92, TSH 516, FO 30.9, Cepec 2004 e JVP 01.

Para o número de vassouras vegetativas, cujas médias estiveram entre 0,15 e 11,8 vassouras/planta/ semestre, os melhores desempenhos entre os das variedades mais produtivas foram os dos clones: $\mathrm{PH}$ 114, CCN 10, FG 110, FL 78, FL 76, CCN 51, Cepec 2002, BN 34, e Vencedora 20. Os piores foram os dos clones: JVP 01, PS 1319, CSG 70, SJ 02, SL 06 e VT 10 , mas todos tiveram menos de 6,1 vassouras/planta/ semestre. E apenas um clone, dentre todos os listados, teve média superior a 10 vassouras por planta por semestre, o FT 500. Também para as primeiras variedades só houve destaque negativo para o TSH 516 e o EET 397.

As porcentagens médias de perda de frutos por vassoura não foram muito altas, variando de 1,87 a 20,70. Mas a presença, novamente, das variedades mais cultivadas, PS 1319 e primeiras variedades resistentes, a exceção do TSH 1188 , entre os 
materiais com maiores perdas, confirma a importância dos processos de seleção recorrente que estão sendo conduzidos pelo Cepec para a ampliação do nível e da durabilidade da resistência à vassoura de bruxa e outras doenças, pela associação de diferentes genes ligados a estes caracteres (Lopes et al., 2011; Benjamim et al., 2016; Pimenta Neto et al., 2018; Silva et al., 2010; Rodrigues, Pires \& luz, 2020; Yamada et al., 2014).

Dentre os clones que tiveram as produções mais altas, as menores porcentagens de perda de frutos por vassoura foram as de: SL 06 (um dos com maior número de vassouras totais), CSG 70, PH 114, RLF 1938, FL 78, FL 89, SJ 02, CCN 51, VT 05 e FL 76. Já as maiores foram de: MCB 09, VT 10, PS 1910, PS 1319, e Cepec 2002.

No geral, os mais baixos valores foram apresentados pelos clones: T 11, MAC 01, SL 06, Cepec 2007, CSG 70, PH 114, SP 50, PH 114, RLF 1938 e Eqx 107. Os valores mais altos foram os de: MCB 09, CP 49, PH 09, TSH 565, EET 397, JVP 01, FT 500, VT 10, CA 1.4 e Cepec 42.

Para a perda de frutos por podridão parda, também apresentada na Tabela 3, houve médias corrigidas de clones entre $-3,08$ e $21,55 \%$, e, dentre os clones de maiores produções, as menores porcentagens de perda de frutos por vassoura foram as do FL 78, Vencedora 20, FL 89, FSH 42, BN 34, CSG 70, FA 13, SL 06, FL 76, PH 114, RLF 1938, FG 110 e PS 1910. As maiores foram as dos clones: PS 5784, JVP 01, MCB 09, e VT 10.

Para todos os clones listados, FL 78, ST 01, Vencedora 20, FL 89, PS 1.6, FSH 42, FSU 01, BN 34 e CSG 70 tiveram as menores médias de perda, e CP 49, BP 41, FB 206, CCN 16, SC 75, PS 5784 as maiores.

Entre as primeiras variedades indicadas o TSH 1188 teve a menor média de perdas, e não houve uma clara distinção para a incidência de podridão parda nestas variedades em relações aos demais clones.

\section{Conclusões}

Há grandes diferenças entre os clones avaliados, para as variáveis: produção, número de vassouras vegetativas, número de vassouras de almofada floral, porcentagem de frutos com vassoura de bruxa e porcentagem de frutos com podridão parda; e diferentes clones evoluíram de maneira diferente para as características consideradas, com o aumento da idade.

Ocorrem diferenças entre clones quanto à adaptação para produção e incidência de doença para os diferentes ambientes.

Entre as variedades atualmente recomendadas pela Ceplac para plantio comercial as variedades com maior produção foram: FA 13, SJ 02, CCN 51, PS 1319, CEPEC 2002, CCN 10 e Vencedora 20.

Produziram significativamente mais que a variedade PS 1319, uma referência para alta produtividade, as variedades comerciais FA 13, CCN 51 e SJ 02, e os clones PS 5785, VT 05, RLF 1938, VT 10, CSG 70, FL 89, SL 06, BN 34 e FL 76, o que ilustra que o processo de seleção massal conduzido em propriedades rurais na Bahia ainda pode levar a indicação de novas variedades para plantio comercial.

A estrutura experimental utilizada para a avaliação dos clones mostrou-se eficiente, permitindo a diferenciação estatística para diferenças numéricas de produção não muito grandes, mesmo para o caso de repetições de clones em poucos locais.

\section{Agradecimentos}

Agradecemos aos cacauicultores e trabalhadores rurais da região cacaueira da Bahia pelo trabalho de seleção da maioria dos clones aqui avaliados, aos cacauicultores por permitirem a condução deste estudo em suas propriedades e ao FINEP e MAPA pelo financiamento das atividades de avaliação.

\section{Literatura Citada}

ALBUQUERQUE, P. S. B. et al. 2010. Novel sources of witches' broom resistance (causal agent Moniliophthora perniciosa) from natural populations of Theobroma cacao from the Brazilian Amazon. Euphytica (Netherlands)172(1):125-138.

BARTLEY, B. G. 1994. A review of cacao improvement. Fundamental methods and results. In: Proceedings of the Internation Workshop on Cocoa Breending Strategies, Kualla Lumpur, Malaysia, 1994. pp.16.

BENJAMIM, C. S. et al. 2016. Cacao families and parents selected as resistant to natural infection 
of Moniliophthora perniciosa. Crop Breeding and Applied Biotechnology (Brasil) 16(2):141-146.

GRAMACHO, K. P. et al. 2012. Breakdown of Scavina resistance in Bahia caused by the evolution of Moniliopthora perniciosa. In: 17th International Cocoa Research Conference, 2012, Yaounde Cameroon. Proceedings. Lagos, Nigeria, COPAL.

LOPES, U. V. et al. 2011. Cacao breeding in Bahia, Brazil: Strategies and results. Crop Breeding and Applied Biotechnology (Brazil) 11(SPE):73-81.

PAIM, V. R. L. M. et al. 2006. Sources of resistance to Crinipellis perniciosa in progenies of cacao accessions collected in the Brazilian Amazon. Scientia Agricola (Brasil) 63(6):572-578 .

PEREIRA, J. L. 1996. Renewed advance of Witches' broom disease of cocoa: 100 years later. In: $12^{\text {th }}$ International Cocoa Research Conference, 1996. Salvador, Brazil, Proceedings. Lagos, Nigeria, COPAL.

PIMENTA NETO, A. A. et al. 2018. Selection of cocoa progenies for resistance to witches' broom. Tropical Plant Pathology 43:381-388.

PIRES, J. L. 2003. Avaliação quantitativa e molecular de germoplasma para o melhoramento do cacaueiro com ênfase na produtividade, qualidade de frutos e resistência a doenças. Tese Doutorado. Universidade Federal de Viçosa, Viçosa, MG. 326p.

PIRES, J. L. et al. 2009. Association among sources of resistance to witches' broom disease for the increment of the level and durability of the character In: 16th International Cocoa Research Conference, Bali, Indonésia. 2009. Proceedings. Lagos Nigeria: COPAL/CATIE. pp.431-435.

PIRES, J. L. et al. 2012. New genes of resistance to witches' broom identified by the behavior of different clones over time In: 17th International Cocoa Research Conference. 2012. Proceedings. Lagos, Nigeria, COPAL.

POUND, F. J. 1938. Cacao and witches' broom disease of South America, with notes on other species of Theobroma: report on a visit to Equator, the Amazon Valley and Colombia, April 1937-April 1938. Port of Spain. 58p.

SAS INSTITUTE INC. 1988. SAS/STAT User's Guide. Release 6.03. Cary, NC: SAS Institute Inc. pp. 1028

SILVA, S. D. V. M. et al. 2010. Parent selection for cocoa resistance to witches' broom. Pesquisa Agropecuária Brasileira 45(7):680-685.

RODRIGUES, G.; PIRES, J. L.; LUZ, E. D. M. N. 2020. Association of genes from different sources of resistance to major cacao diseases. Revista Ceres (Brasil) 67:383-394.

YAMADA, M. M. et al. 2014. Ocorrência de vassoura-de-bruxa em progênies de cacaueiro selecionadas pelo programa de melhoramento na Estação Experimental Joaquim Bahiana. Agrotrópica (Brasil) 26(3):197-202. 